\title{
As concepções e experiências de auxiliares de educador no trabalho com TEA: oficina para criação de recursos lúdicos*
}

\author{
Experiences and Conceptions of Education Assistant with ASD \\ Students: A Workshop to Build Playful Resources
}

Las concepciones y experiencias de asistentes de educación en el trabajo con TEA: taller para creación de recursos lúdicos

\author{
Denise Vieira Taborda** , Eloisa Capeletto***, \\ Lucas Demarchi Gomes**** y Allan Henrique Gomes*****
}

\begin{abstract}
RESUMO
Tendo em vista as limitações impostas pelo TEA, essa pesquisaintervenção utilizou dos conhecimentos do programa TEACCH para fundamentar uma oficina estética com o objetivo de verificar como a experiência de criação de recursos lúdicos para estudantes com TEA se dá por um grupo focal de auxiliares de educador que atuam na rede básica de ensino. A oficina ocorreu nas dependências de uma instituição referência no atendimento ao TEA com duração de aproximadamente três horas e contou com seis participantes. Como resultados, destacam-se: a problematização do cargo de auxiliar de educador; o descontentamento com a não valorização do lúdico na educação e a relevância da ludicidade no fazer pedagógico; o desconhecimento do
\end{abstract} Palavras-chave: autismo; oficina criativa; programas educacionais; formação de professores; pesquisa ação.

\footnotetext{
* Os autores reconhecem e agradecem o apoio de todos os profissionais que se disponibilizaram a participar da oficina espontaneamente e, em especial, a instituição que cedeu o espaço para que o estudo pudesse ser realizado. Ressalta-se que essa pesquisa foi financiada pelos próprios pesquisadores.

** Discente do Curso de Psicologia da Universidade da Região de Joinville (UNIVILLE). Correspondência: dvt.denise@gmail.com

*** Discente do Curso de Psicologia da Universidade da Região de Joinville (UNIVILLE). Correspondência: eloisacapeletto@gmail.com

**** Discente do Curso de Psicologia da Universidade da Região de Joinville (UNIVILLE)

***** Doutor em Psicologia pela Universidade Federal de Santa Catarina - UFSC. Docente do curso de Psicologia na Universidade da Região de Joinville (UNIVILLE)
} 
TEACCH e a apropriação de pressupostos do programa antes e depois da oficina.

\begin{abstract}
Considering the limitations imposed by ASD, this intervention research study uses the TEACCH program to establish an aesthetic workshop and focus group of public elementary school education assistants to explore the experience of creating playful resources for ASD students. The workshop took place on the premises of a TEA reference institution with six participants, and lasted approximately three hours. As a result, the following aspects stood out: the problematization of the position of education assistant; discontent with the lack playfulness in early childhood education and the relevance of playfulness in the pedagogic practice; the lack of knowledge of TEACCH and the appropriation of program assumptions before and after the workshop.
\end{abstract}

\section{RESUMEN}

Considerando las limitaciones impuestas por el TEA, esta investigación-intervención utilizó los conocimientos de la metodología TEACCH para fundamentar un taller estético con el objetivo de verificar cómo la experiencia de crear recursos lúdicos para estudiantes con TEA es impartida por un grupo focal de asistentes de educación que se desempeñan en la red básica de enseñanza. El taller se desarrolló en las dependencias de una institución de referencia en la atención del TEA, con una duración de aproximadamente tres horas y contó con seis participantes. Como resultados, se destacan: la problematización del cargo de asistente de educación; el descontento con respecto a la no valorización del aspecto lúdico en la educación y la relevancia de este en el quehacer pedagógico; el desconocimiento del TEACCH y la asunción de premisas sobre el programa antes y después del taller.
Key words: autism; creative workshop; educational programs; teacher education; action research.

Palabras clave: autismo; taller creativo; programas educacionales; formación de profesores; investigación acción. 
Ensino, aprendizagem e desenvolvimento são processos complexos e interligados. O fundamental à escola/educação, desde a educação infantil até a pós-graduação, é ensinar o estudante para que este aprenda e também tenha mudanças em seu campo de possibilidades de desenvolvimento (Facci, 2004). Partindo dessa afirmação, entende-se que o ambiente educacional não se restringe apenas a proporcionar a aquisição de conhecimentos científicos, mas se propõe a integrar os indivíduos no meio social, aperfeiçoando suas habilidades motoras e demais necessidades que se expressam em diferentes contextos (Salomão \& Martini, 2007).

O Transtorno do Espectro Autista - TEA compreende uma gama de condições que tem início na infância, sendo normalmente diagnosticado antes dos cinco anos de idade, e tende a persistir na adolescência e na idade adulta. $\mathrm{O}$ transtorno é caracterizado por algum grau de comportamento social prejudicado, além da comunicação e linguagem, e uma faixa estreita de interesses e atividades que são únicas para o indivíduo e realizadas repetidamente. Na grande maioria dos casos relata-se a ausência de comunicação verbal e, nos casos de Autismo Leve, as dificuldades se concentram principalmente no que diz respeito à pragmática (Kwee, Sampaio \& Atherino, 2009; WHO, 2017).

No que se refere ao nível de funcionamento intelectual em indivíduos com TEA, a World Health Organization (WHO, 2017) traz um dado extremamente variável, estendendo-se desde um profundo comprometimento até níveis de inteligência considerados acima da média. Na mesma perspectiva, entende-se que muitos podem viver de forma independente, enquanto outros têm deficiências graves e requerem cuidados e apoio ao longo de toda a vida.

Dentro do quadro, algumas comorbidades estão frequentemente presentes, como é o caso da epilepsia, depressão, ansiedade e transtorno do déficit de atenção e hiperatividade - TDAH (WHO, 2017). O fato de o autismo envolver uma gama bastante variada de doenças com diferentes quadros clínicos e não ter uma explicação etiológica comum é alvo de grandes controvérsias para diversos autores. O que se intensifica diante das frequentes alterações na descrição e categorização do transtorno (Kwee, Sampaio \& Atherino, 2009). 
Dito isso, Kwee (2006) afirma que os desconhecimentos de especificidades que permeiam o TEA levam a diversas abordagens clínicas e terapêuticas que são, por vezes, antagônicas. Por essas razões que as intervenções para pessoas com TEA precisam considerar particularidades inerentes de cada quadro individual e serem acompanhadas de ações amplas para tornar os ambientes físicos, sociais e de atitudes mais acessíveis, inclusivos e favoráveis ao sujeito. Intervenções psicossociais baseadas em evidências, tais como tratamento comportamental e programas de treinamento de habilidades dos pais, podem reduzir as dificuldades na comunicação e no comportamento social, com impacto positivo no bem-estar e na qualidade de vida das pessoas com TEA e seus cuidadores (WHO, 2017).

Uma forma de intervenção que merece destaque consiste no programa Treatment and Education of Autistic and related Communicattion handicapped Children - TEACCH, criado em 1966, na divisão de Psiquiatria da Escola de Medicina da Universidade da Carolina do Norte, nos Estados Unidos da América, por Eric Shopler e colaboradores. Sua criação se deu por um projeto de pesquisa que questionava a prática clínica voltada para o TEA, a qual pressupunha que o transtorno tinha gênese emocional e deveria ser realizado através dos princípios da psicanálise. As bases epistemológicas do TEACCH, assim, trouxeram uma perspectiva distinta, que converge para uma prática funcional e pragmática vindas da Teoria Behaviorista e da Psicolinguística (Kwee et al., 2009).

O TEACCH é um programa que envolve as esferas de atendimento educacional e clínico, em uma prática com abordagem psicoeducativa. Ele tem por finalidade a construção e o desenvolvimento de instrumentos de avaliação diagnóstica e psicoeducacional, treinamento de profissionais, orientação a pais, além da criação de locais de atendimentos, escolas, residências assistidas e programas de acompanhamento profissional (Kwee, 2006).

Dos objetivos do programa destacam-se os que visam promover a melhora de todas as habilidades para o viver por meio de técnicas específicas e entender e aceitar as limitações impostas pelo transtorno, planejando estruturas ambientais que possam compensá-lo. A base do programa se dá a partir da avaliação que permita a compreensão das habilidades atuais e emergentes do estudante e quais os métodos 
eficazes para desenvolvê-las. Além disso, prioriza-se o trabalho das famílias como coterapeutas de uma equipe com configuração multiprofissional (Kwee, 2006).

Tendo em mente os diferentes graus de severidade do TEA, o TEACCH se organiza em quatro níveis que exigem conhecimentos em uma escala crescente e cumulativa do estudante. O primeiro nível trabalha com atividades iniciais e concretas, que exigem habilidades de organização motora, funcionalização das mãos, movimento coordenado e ritmado de trabalho. O segundo nível, por sua vez, traz exercícios com exigência cognitiva, como a discriminação de itens e reconhecimento de objetos, mas ainda tendo em vista elementos concretos. No nível três, o estudante já apresenta habilidades de planificação e tem-se também o início da função simbólica, categorização, discriminação de imagens, evocação de conceitos abstratos, combinação de objetos com imagens. Por fim, a habilidade da leitura com significado já é dominada, permitindo uma prática mais complexa e elaborada (Fonseca, 2016).

Nesse processo o professor é uma peça chave, devendo ser encarado como um elemento essencial e fundamental, visto que são os professores os principais sujeitos a utilizarem dos princípios do programa TEACCH e é na instituição escolar que se gera, "direta ou indiretamente, em cada indivíduo singular, a humanidade que é produzida histórica e coletivamente pelo conjunto dos homens" (Saviani, 2011, p. 25).

Segundo Marques (2012), o lúdico não é explorado de forma adequada e nem utilizado quando se observam necessidades educacionais específicas. Um estudo realizado por Lucisano, Novaes, Sposito e Pfeifer (2017) traz dados que possibilitam esclarecer quais os métodos lúdicos são mais convenientes para a interação com a criança com TEA. De forma geral, o lúdico abrange as brincadeiras e os jogos que fazem parte do desenvolvimento humano. Ele pode estar presente em sala de aula, como uma eficiente metodologia na prática docente, favorecendo o processo de ensino e de aprendizagem (Lucisano et al., 2017).

Partindo dessas informações, verifica-se a demanda presente de trabalhar um fazer pedagógico que tenha como finalidade significar o lúdico e apropriá-lo às particularidades dos estudantes com TEA. 
Essa apropriação ocorre, não somente por meio de uma fundamentação teórica sobre a educação especial, mas a partir das experiências e vivências dos professores junto aos estudantes em sala de aula e das concepções que os cercam.

Compreendendo então a singularidade da demanda dos estudantes com TEA e tendo o professor como protagonista, uma vez que o espaço escolar ocupa um longo período do desenvolvimento infantil, esse estudo visou investigar a experiência criadora de recursos lúdicos para estudantes com TEA. Concomitantemente, buscou-se analisar os significados que esse professor dá aos materiais lúdicos no desenvolvimento e avanços do quadro do estudante com TEA e como a sua experiências o auxilia em sua criação. Para tanto, foi feita uma oficina com auxiliares de educador da rede básica de ensino de Joinville, utilizando dos conhecimentos do programa TEACCH - o qual foi introduzido aos professores de forma teórica e prática.

A opção por uma pesquisa-intervenção se deu na medida em que se compreende que nesta perspectiva são abertas aos participantes possibilidades de reflexão sobre formas e conteúdos. Bem como, nesta modalidade de investigação, significados e sentidos peculiares podem ser atribuídos ao processo de aprendizagem, e ainda, de que maneira o professor, como mediador do conhecimento, pode atuar por meio do enfoque na avaliação lúdica, na amenização da sintomatologia supracitada.

\section{MÉTODO}

O presente estudo teve abordagem qualitativa e utilizou-se do método da pesquisa-intervenção. Segundo Damiani (2012, p. 1), a pesquisa-intervenção visa "planejar, implementar e avaliar práticas pedagógicas inovadoras" de maneira a investigar a vivência de coletividades em sua diversidade qualitativa (Rocha \& Aguiar, 2003). Para tanto, são realizadas

interferências (mudanças, inovações) [...] por professores/pesquisadores, em suas práticas pedagógicas. Tais interferências são planejadas e implementadas com base em um determinado referencial teórico e objetivam promover avanços, melhorias, nessas práticas, além de pôr à prova tal referencial, contribuindo para o 
avanço do conhecimento sobre os processos de ensino/aprendizagem neles envolvidos (Damiani, 2012, p. 3).

Em consonância com o descrito acima, é esclarecido que a criação de recursos lúdicos para estudantes com TEA constitui uma inovação na prática pedagógica dos participantes. O referencial teórico metodológico utilizado para a criação de tais recursos baseia-se no programa TEACCH. Para possibilitar essa construção e compilação de conhecimentos, foi realizada uma oficina estética, entendida como um dispositivo relevante no trabalho com grupos e na pesquisa-intervenção. Estas são mediadas por atividades criadoras que agem na produção de subjetividade e se estabelecem como espaços de aprendizagem (Reis \& Zanella, 2015). A técnica de pesquisa utilizada na oficina foi a do grupo focal. Essa técnica objetiva, a partir de trocas realizadas no grupo, captar sentimentos, atitudes, significados e reações de uma forma que não é possível através de outros métodos de pesquisa em ciências sociais e humanas (Gatti, 2005).

Para além do TEACCH, a psicologia com a sua compreensão de dinâmicas grupais, permitiu que os condutores da pesquisa focalizassem as discussões e as trocas de experiências que emergiram no desenvolver do grupo. O grupo é concebido como um lugar de conversa e de um conhecimento/aprendizagem que se produz no encontro com outro. Os sujeitos do grupo reunem-se em torno de uma tarefa e através dela tomam para si um objeto problemático, sobre o qual conversam, fazem descobertas sobre si, operam significados e ultrapassam obstáculos (Castanho, 2012).

A condução do grupo foi feita por um dos pesquisadores que teve o papel de moderador das discussões e realizou as intervenções. Outro pesquisador atuou como relator, não interferindo no grupo e fazendo anotações em diário de campo sobre o processo grupal, pontuações dos participantes e também de respostas não-verbais, além de ocuparse com a gravação de áudio na realização do grupo focal. Tais dados foram transcritos e submetidos à análise.

A oficina estava planejada inicialmente para ocorrer em dois encontros com duração de uma hora e meia cada, porém, devido a dificuldade de liberação dos professores por parte das escolas, apenas um encontro foi realizado, com duração de 3 horas. Dessa forma, houve- 
ram poucas alterações no andamento da oficina, que se desenvolveu da seguinte forma: 1) apresentação dos pesquisadores e objetivos da oficina; 2) dinâmica de integração: apresentação dos participantes e de seus estudantes com TEA; 3) dinâmica de sensibilização com recurso audiovisual; 4) apresentação sobre o programa TEACCH; 5) planejamento e prática criadora; 6) grupo focal para apresentar os materiais lúdicos desenvolvidos, com questionamentos acerca da prática criadora e experiências; e 7) feedback da oficina.

Algumas das questões realizadas no decorrer do grupo focal e que possibilitaram a roda de conversa foram: quais as peculiaridades de destaque no material criado? De que maneira esse material pode auxiliar o desenvolvimento do estudante com TEA? De que forma a sua experiência como professor(a) te auxiliou na criação desse material? Qual o papel que você, como professor, tem no desenvolvimento dos estudantes com TEA? Você acredita que esse tipo de oficina possa subsidiar o trabalho do professor de estudantes com TEA? Logo após, foi dado o encaminhamento para o feedback, no qual procurou-se saber como foi para cada participante participar da oficina, os significados e significantes que eles davam a esta experiência e a importância da existência de mais encontros como o que se deu.

\section{Participantes}

A oficina foi realizada com professores da rede básica de ensino de Joinville nas dependências de uma instituição referência no atendimento ao TEA. Esta disponibilizou seu espaço e concedeu o contato de profissionais que em algum momento buscaram dialogar com a instituição para entender o método pedagógico da escola.

Seis participantes estiveram presentes, o que condiz com a amostra ideal recomendada por Gatti (2005) para a realização de um grupo fo$\mathrm{cal}$, entre seis e doze participantes. Todas as participantes da pesquisa eram do sexo feminino, possuem graduação em Pedagogia completa ou em andamento e ocupam o cargo de auxiliar de educador para crianças do ensino fundamental na rede municipal. Cinco das participantes (P1, P2, P3, P4 e P6) trabalhavam na mesma escola e a restante (P5) atuava em outro local como auxiliar de educador e na instituição especializada em TEA no qual o estudo se deu. Vale esclarecer que apenas $\mathrm{P} 4$ não tinha contato diário com pelo menos um estudante com 
TEA - ela, entretanto, participava dos rodízios de professor empregado pela escola e em alguns momentos auxiliava estudantes com o transtorno.

Na Tabela 1 pode ser encontrado um resumido histórico do perfil profissional e a relação que as participantes tem com o TEA.

Tabela 1

Histórico da relação das profissionais com o TEA

\begin{tabular}{ll}
\hline Profissional & \multicolumn{1}{c}{ Relação } \\
\hline P1 & $\begin{array}{l}\text { Trabalha na rede municipal de ensino há dois anos e é } \\
\text { auxiliar do Cascão, estudante do } 4^{\circ} \text { ano com TEA. }\end{array}$ \\
\hline P2 & $\begin{array}{l}\text { Atua há quase nove anos na educação e nesse percurso já } \\
\text { teve alguns estudantes com TEA e outras deficiências. Já } \\
\text { fez estágio na instituição em que a oficina ocorreu e agora } \\
\end{array}$ \\
$\begin{array}{l}\text { é auxiliar da Mônica, que está com nove anos e tem seu } \\
\text { neurodesenvolvimento comprometido pelo TEA. }\end{array}$ \\
\hline P3 & $\begin{array}{l}\text { Encontra-se há quatro anos na rede e durante esse período } \\
\text { já trabalhou com Horácio e Cebolinha, ambos estudantes } \\
\text { com TEA. }\end{array}$ \\
\hline P4 & $\begin{array}{l}\text { Auxiliar de Chico Bento, que está no quarto ano e possui } \\
\text { paralisia cerebral, além de sofrer com episódios constantes } \\
\text { de convulsão. Ela atua na rede há apenas dois meses e } \\
\text { comenta ter contato esporádico com os estudantes com } \\
\text { TEA. }\end{array}$ \\
\hline P5 & $\begin{array}{l}\text { É professora na instituição especializada há um ano e na } \\
\text { rede municipal auxilia um estudante com TDAH. }\end{array}$ \\
\hline P6 & $\begin{array}{l}\text { Está em seu segundo contrato, tendo cada um a duração de } \\
\text { dois anos. Além de já ter trabalhado com quatro crianças } \\
\text { com TEA na escola, sendo elas Magali, Mônica, Bidu e } \\
\text { Cebolinha, P6 também tem um caso de TEA em sua família. }\end{array}$ \\
\hline
\end{tabular}

Segundo a Secretaria de Gestão de Pessoas (Joinville, 2014), ter ao menos o magistério como formação é requisito básico para ser auxiliar de educador. Esse profissional é responsável pelo suporte ao professor na execução de atividades pedagógicas junto a crianças e adolescentes e o mesmo poderá atender aos estudantes com deficiência e transtornos globais de desenvolvimento, os quais se mostram dependentes em atividades da vida diária de higiene, alimentação e locomoção.

Como parte do processo para compreender as concepções e vivências das profissionais, são citados por elas os nomes dos estudantes 
com os quais trabalham cotidianamente. Esses, por sua vez, foram renomeados com personagens da Turma da Mônica, do cartunista brasileiro Mauricio de Sousa. São eles: Cascão, Mônica, Horácio, Cebolinha, Chico Bento, Magali, Mônica, Bidu e Cebolinha.

Faz-se importante ressaltar que as participantes tiveram seu anonimato preservado por meio da assinatura do Termo de Consentimento Livre e Esclarecido - TCLE e do Termo de Autorização de Uso de Imagem e/ou Voz, sendo que a pesquisa somente teve início após aprovação no Comitê de Ética em Pesquisa - CEP, sob parecer número 2.757.919. As participantes também receberam uma declaração de participação emitida pela Universidade da Região de Joinville - Univille, como forma de justificarem a ausência em seus locais de trabalho e comprovarem a qualificação profissional.

\section{Análise dos dados}

O método para analisar os resultados obtidos a Análise de Conteúdo proposta por Franco (2012, p. 12), cujo ponto de partida "é a mensagem, seja ela verbal (oral ou escrita), gestual, silenciosa, figurativa, documental ou diretamente provocada". Para Marconi e Lakatos (2003) essa análise refere-se ao processo de conhecimento de determinada realidade e implica o exame sistemático dos elementos, permitindo observar os componentes de um conjunto e perceber suas possíveis relações. Nesse sentido, na Análise de Conteúdo deve ser principalmente interpretado o sentido que um indivíduo atribui às mensagens (Franco, 2012).

A primeira fase da Análise de Conteúdo consistiu na pré-análise. Nesta etapa, os dados obtidos na transcrição e diários de campo foram organizados e explorados sistematicamente, mas não de forma estruturada. Na segundo fase foram efetuados recortes do texto em unidades comuns denominadas de categorias, as quais foram tabeladas. "A categorização é um operação de classificação de elementos constitutivos de um conjunto, por diferenciação seguida de um reagrupamento baseado em analogias, a partir de critérios definidos" (Franco, 2012, p. 63). Tais critérios podem ser semânticos, sintáticos, léxicos ou, ainda, expressivos. Por último, foi feito o tratamento dos dados, com a finalidade de interpretar os resultados à luz de teorias explicativas (Franco, 2012). 


\section{Resultados e discussões}

A partir dos dados coletados na oficina emergiram sete categorias de análise, sendo seis delas analisadas com maior enfoque. Tais categorias correspondem a: experiência docente, concepções acerca dos estudantes, práticas pedagógicas, o trabalho com o lúdico, questões políticas relacionadas ao cargo de auxiliar de educador, a experiência criadora e o relacionamento entre família e escola/família e estudante. Esta última categoria não constituiu escopo para esse artigo, mas pode ser esmiuçada em pesquisas posteriores. Os subtítulos dessa sessão não necessariamente correspondem às categorias de análise.

\section{O perfil profissional do auxiliar de educador}

Compreendendo suas concepções e práticas, as profissionais participantes da pesquisa, que não possuem os mesmos direitos e prerrogativas de professores do ensino regular, problematizam o seu cargo. P2, por exemplo, cita o rodízio realizado entre os auxiliares de educador e os estudantes e a ausência de tempo hábil destinado à discussão e matriciamento dos casos, o que possibilitaria a troca de experiências e um trabalho de melhor qualidade. P4, sob a mesma reflexão, coloca a ausência desse tempo como um direito que está sendo aviltado e P3 complementa que o termo "auxiliar de educador" não seria condizente com o trabalho da categoria, uma vez que seus trabalhos vão muito além do auxílio ao estudante.

Nesse sentido, P5 que tem experiência na rede municipal e na instituição referência em TEA, compara os diferentes recursos que subsidiam o processo de ensino-aprendizagem e desenvolvimento em ambos os locais. Ela verbaliza: "[...] eu sinto diferença que eu trabalho no regular e trabalho aqui (sic instituição especializada). E aqui nós temos psicólogo, aqui nós temos fono, aqui temos... meu, é o sonho que toda escola tivesse". Além destes profissionais, P5 aponta para a necessidade de se ter acompanhamento com nutricionista para amenizar a seletividade alimentar dos estudantes com TEA, além de uma equipe técnica que englobe terapeuta ocupacional, psicólogo e professores especializados. Outra demanda levantada na rede municipal vai ao encontro da última consideração, uma vez que as profissionais percebem a necessidade de educação continuada, mas a recebem do município apenas no primeiro ano de contrato. 
A Lei de Diretrizes e Bases da Educação Nacional - LDB, dada inicialmente pela a Lei no 9.394 de 1996, passa por atualizações desde a sua promulgação. A versão mais recente considera, em seu capítulo V, Art. 58, o acesso à educação regular para educandos com deficiência, transtornos globais do desenvolvimento e altas habilidades ou superdotação (Brasil, 2013), incluindo, quando necessário, serviços de apoio especializado na escola regular, para atender peculiaridades com início na educação infantil e estendendo-se ao longo da vida (Brasil, 2018). Vale ainda frisar que, em seu artigo 59, inciso III, explana-se a necessidade de "professores com especialização adequada em nível médio ou superior, para atendimento especializado, bem como professores do ensino regular capacitados para a integração desses educandos nas classes comum" (Brasil, 2013, web).

\section{Concepção sobre o estudante com TEA}

Os participantes da pesquisa, ao compreenderem seus estudantes, trazem muito das concepções do TEA dadas pelos critérios diagnósticos do DSM V (DSM-5, 2014) e da organização mundial da saúde (WHO, 2017) e relacionam ao que é ou não verídico em seu cotidiano. Percebe-se uma imagem idealizada do sujeito que tem uma patologia que limita o seu processo de desenvolvimento, o que pode, de maneira geral, interferir positiva ou negativamente no trabalho docente.

Para confirmar tal pensamento explana-se que P1 define Cascão como uma criança muito carinhosa, que gosta de beijos e abraços. Em contrapartida, P2 cita que Mônica não aceita nenhuma das duas atitudes e P3 traz que Cebolinha só permite ser abraçado, e que este verbaliza: "abraço pode, beijo não pode porque espinha". Essas considerações vêm ao encontro de critérios diagnósticos de TEA DSM-5 (2014) acerca da hiper-reatividade a estímulos sensoriais (critério B) e também no que diz respeito ao déficit na interação social (critério A), que é maior nos estudantes Cebolinha e Mônica do que em Cascão.

P6, ao mencionar Cebolinha, também aponta para a demanda da seletividade. Uma de suas atividades favoritas consistia em pintar e desenhar, entretanto, ele utilizava apenas uma cor para realizá-las. P6 relaciona essa característica a padrões restritos e repetitivos de interesses ou atividades em autista, que consta no critério A do DSM-5 (2014). P3 complementa que no atual momento o estudante já pintava com 
três cores diferentes - branco, preto e vermelho - que são aquelas que representam o Mickey, seu personagem favorito.

P2 e P6 trazem peculiaridades quanto a Mônica, que apresenta o transtorno num nível mais limitante. O TEA pode ser classificado em três níveis diferentes: em que o sujeito necessita de apoio (nível 1), de apoio substancial (nível 2) e de apoio muito substancial (nível 3) (DSM-5, 2014). Dentre todos os estudantes, apenas Mônica aparenta não estar no nível 1. Conforme as participantes, seu laudo possui cerca de 50 páginas, o que revelaria especificidades quanto as suas limitações e potencialidades. Mônica não sustenta contato visual, não fala muito e apresenta rompantes de agressividade.

Outros dois casos são mencionados por P6, de Magali e Cebolinha. A participante cita que Magali "se tu conhece ela tu pensa que ela não é autista, porque ela é totalmente independente, é a mais inteligente da sala". Remete-se aqui a importância do conhecimento dos critérios diagnósticos para se ter uma percepção aguçada das alterações típicas do TEA. Cebolinha, numa mesma perspectiva, é citado como um estudante "extremamente inteligente, e né, ele falava mais de uma língua, muito esperto, muito querido". Nesses dois casos, nega-se a existência de comprometimento intelectual concomitante (DSM-5, 2014).

A clareza dos especificadores individuais, que compreende toda a sintomatologia do sujeito com TEA, é importante para determinar a escolha e a provisão de serviços mais adequada (DSM-5, 2014). O programa TEACCH, sob essa ótica, concebe a avaliação individualizada para intervenção junto do estudante, que visa examinar as necessidades, habilidades emergentes e o que se espera para a idade e seriação escolar (Fonseca, 2016).

\section{O lúdico na educação e sua relação com o TEA}

P6 levanta apontamentos sobre a aceleração e antecipação do processo de aprendizagem na educação infantil. Ela atesta que na fase inicial de escolarização, os estudantes deveriam ser permitidos a ter seu desenvolvimento amparado por recursos e métodos de ensino-aprendizagem que tivessem como pilar a ludicidade. A partir do lúdico o sujeito testa e desenvolve suas habilidades, criatividade, iniciativa e autoconfiança, e também internaliza regras de conduta e desenvolve um sistema de valores que orientem seu comportamento (Lucisano et al., 2017). 
Lucisano et al. (2017) relata que em algumas escolas o lúdico se restringe somente às aulas de Recreação e de Educação Física, sendo tratado como forma de entretenimento, divertimento e lazer. As participantes da oficina, durante o grupo focal, convergem para a importância da sensibilidade, por parte de quem ministra as aulas, de trabalhar com o lúdico no desenvolvimento de habilidades sociais, motoras, afetivas e cognitivas. Salomão e Martini (2007), indo na mesma direção, trazem que o educador, em seu fazer pedagógico, deve ter em sua percepção às contingências em sala de aula para que se possam criar condições de ensino e saber. Para isso, diferentes atividades podem ser utilizadas e criadas para a ampliação das redes e significados do indivíduo.

Nesse sentido, P6 faz uma crítica ao tempo elevado em que os estudantes permanecem sentados e também à estrutura e organização das salas de aula. Ela entende que um plano pedagógico que visa ensinar diversos conteúdos em tempo reduzido, necessita também de um tempo excessivo de atenção e estudos por parte das crianças. Essas, entretanto, "não estão prontas e a gente quer colocar elas naquele mundo, empurrar e quer que elas se acostumem" (P6). Em decorrência desse fato são desenvolvidas patologias de diversos níveis, além da perceptível angústia dos estudantes. P6 afirma que a criança resolve seus conflitos através da brincadeira e a não estimulação do lúdico seria uma das vias para o alto índice de adolescentes com depressão. Assim "na hora que ele precisa resolver um conflito na vida adulta, na adolescência, ele não vai conseguir, porque ele não foi trabalhado na infância" (P6).

Essa última afirmação condiz com o que Hosokawa e Wiezzel (2013) trazem em seu estudo, o qual afirma que uma das formas mais eficientes para o auxílio da criança em seu desenvolvimento emocional é o brincar. O lúdico, assim, propicia a expressão de angústias, a elaboração de situações que foram traumáticas e dolorosas e permite ao sujeito vivenciar situações que não são permitidas na vida real. Tal concepção foi expressa por P6, a qual diz que "a criança resolve os conflitos dela na brincadeira, por isso hoje se briga tanto para se manter o lúdico na educação".

Pensando nos estudantes com TEA e nos seus padrões de comportamentos, interesses e atividades restritos e na sua dificuldade para compartilhar brincadeiras imaginativas e compreender relacionamentos (DSM-5, 2014), debate-se sobre a articulação entre atividades 
pedagógicas e a disponibilidade de recursos lúdicos associados a ela. O programa TEACCH, que é pensado especialmente para estudantes com TEA e foi discutido na introdução deste artigo, visa organizar, estruturar e tornar previsível as atividades pedagógicas e dá enfoque especial ao lúdico na aprendizagem de autistas. Tais estratégias possibilitam a redução da ansiedade e da frustração dos estudantes e a melhora na sua capacidade adaptativa (Fonseca, 2016).

No que se refere à ludicidade e o TEA, Lucisano (2017) traz que: nos jogos de imitação, crianças com e sem TEA apresentam performances semelhantes. $\mathrm{O}$ mesmo fato é verificado quando testada a articulação da atenção. Com relação ao brincar de faz de conta, as crianças com TEA apresentaram valores inferiores no Test of Pretend Play - ToPP - do que crianças sem TEA, o que indica deficiências na comunicação e interação social. O mesmo autor, ao citar o estudo de Hobson et al. (2013 citado por Lucisano et al., 2017), relata que crianças com TEA apresentaram escores significativamente mais baixos na medida composta de qualidades lúdicas aplicada ao ToPP, bem como relativa escassez de pretexto lúdico. Isso se expressa na medida em que as deficiências na comunicação e interação social estão associadas com limitações na qualidade de jogo, mesmo quando habilidades do jogo formal são levadas em conta. Limitação na criatividade e imitação entre os estudantes com TEA se relacionam com sua comunicação e engajamento interpessoal restrito.

Em pesquisa, Tamanaha, Chiari, Perissinoto e Pedromônico (2006) classificaram a atividade lúdica de crianças com TEA e destacaram que mais de $90 \%$ destas utilizam do critério sensório-motor como predominante nas atividades. Isso indica que tais crianças majoritariamente ficaram manipulando livremente peças e objetos por meio de ações sensório-motoras, não dando funcionalidade a elas. Mais do que um possível atraso no desenvolvimento da exploração lúdica, essa característica pode se dar como consequência das estereotipias presentes em sujeitos autistas. Atrela-se o comportamento a alterações da capacidade cognitiva e falhas no desenvolvimento da linguagem (Tamanaha et al., 2006).

Acrescenta-se ainda que o comprometimento na função da linguagem poderia ser explicado por falhas na capacidade simbólica e imaginativa. Sujeitos com TEA demonstram dificuldade acentuada para 
simbolização, o que também os limita no que concerne habilidades de reciprocidade social. Sendo assim, o direcionamento, o incentivo e o modelo conferem alicerces para adequação da aquisição e do desenvolvimento da linguagem (Tamanaha et al., 2006). Essa metodologia proposta corresponde ao que o programa TEACCH também pressupõe no trabalho com estudantes autistas.

\section{A experiência criadora de um recurso lúdico}

Antes de dar início a experiência criadora, realizou-se uma apresentação sobre as principais características do programa TEACCH. As participantes, mesmo tendo o seu primeiro contato com o programa durante a oficina, demonstraram utilizar de vários conhecimentos propostos pelo mesmo em sua prática pedagógica. Nesse sentido, elas contam que costumam buscar conhecimento sobre o TEA em livros e problematizam novamente a necessidade de formação continuada, destacando a necessidade de mais encontros como o proposto pela oficina.

Para o desenvolvimento do recurso lúdico, as participantes foram divididas em duplas e disponibilizou-se uma ampla variedade de materiais recicláveis e de papelaria. Enquanto produziam, elas compartilhavam com as demais suas vivências e impressões sobre o que estavam fazendo.

A respeito da atividade criadora, a primeira equipe (P5 e P6) associou o jogo criado com o nível de desenvolvimento de seus estudantes e sugeriu acrescentar variações no jogo com materiais disponíveis na escola em que leciona. Dessa forma, o material constitui-se também como um recurso sustentável. P6 confirma que pensou de forma pedagógica, baseando-se em sua experiência profissional e trouxe novidades que aprendeu sobre o TEACCH, tal como organizar o material da esquerda para a direita ou de cima para baixo. "Eu não podia confundir eles, eu não podia deixar muito próximo pra não misturar. E eu tinha que criar uma sequência, mesmo que não parecesse, pra que ele se baseasse" (P6).

As participantes da segunda equipe ( $\mathrm{P} 1$ e P4) pensaram em estudantes específicos e o que estavam trabalhando com eles naquele momento (numeral). Elas também sugeriram adaptações que podem ser feitas na funcionalidade dos recursos desenvolvidos, conforme o estudante avança do nível concreto para o abstrato. Além disso, trazem 
vivências que tiveram com os estudantes, que são referidos de forma afetiva por todas as participantes ao longo da oficina. Quando questionadas sobre como seus fazeres pedagógicos podem mudar o futuro dos estudantes da educação especial, $\mathrm{P} 6$ responde:

Depois que eu fui mãe tenho esse olhar maternal assim. É o amor, o cuidado. [...] Tanto o [Cebolinha], que eu fiquei mais tempo e depois a gente mudou, eu me apeguei muito a ele. E eu noto: [...] o nosso cheiro, eles se identificam, dependendo da pessoa. E eu sempre procurei trabalhar dessa forma [...] E pensando na vida dele no futuro. Se ele vai conseguir, porque ele vai precisar ser independente [...] Se tiver algum problema, é pensando nele [...]

Sendo assim, pontua-se que o TEACCH foi acolhido como uma novidade teórica na formação das participantes e a oficina pode ser considerada uma vivência rica na troca de experiências profissionais e produção de subjetividade, visto que não há outros espaços onde elas possam dialogar.

Os dados analisados no presente estudo vão ao encontro do que Gatti (2005) explana sobre a pesquisa com grupos focais, os quais propiciam uma ampla exposição de ideias que trazem a tona respostas mais completas sobre a temática pesquisada e capta diferentes perspectivas e ideias partilhadas. A participação no processo do grupo focal também propiciou um momento de desenvolvimento para as participantes em seus aspectos comunicacionais, cognitivos e afetivos, conforme evidenciado por fatores expressivos da linguagem verbal e não verbal e pela própria dinâmica grupal.

\section{Considerações finais}

Os objetivos desta pesquisa-intervenção foram atingidos, na medida em que a oficina constituiu-se como um tipo de formação continuada e o grupo focal como um dispositivo de trabalho que facilitou as trocas de experiências e vivências. As experiências permitiram aos pesquisadores averiguarem os significados expressos acerca do estudante com TEA e os recursos lúdicos necessários para a sua aprendizagem e desenvolvimento. Foi apontado pelas participantes que momentos de interação aprimora o trabalho realizado com os estudantes, uma vez o trabalho de grupo possibilita descobertas e opera significados. 
Dando destaque ao lúdico, as participantes espontaneamente expressaram seu descontentamento com a não valorização da ludicidade na educação infantil, independente dos estudantes apresentarem ou não algum transtorno prévio. Elas vão contra a proposta de se trabalhar com o lúdico apenas como entretenimento e lazer, e a favor de ampliar a dimensão pedagógica do lúdico, no sentido de propiciar o desenvolvimento de habilidades sociais, motoras, afetivas e cognitivas. Salientam, ainda, que a ludicidade permite aos estudantes elaborarem seus conflitos e lidarem com a ansiedade e frustração.

Com respeito ao TEACCH, as participantes reconhecem que o utilizam em seu fazer pedagógico mesmo sem anteriormente saber da existência de um termo específico para a prática. Adicionando os conhecimentos sobre o programa adquiridos durante a oficina, a experiência criadora das professoras também se fez reflexo de suas experiências e vivências, sendo que os materiais foram criados com base nas especificidades dos estudantes com que elas trabalham ou já trabalharam.

Por fim, compreendendo as possibilidades e limitações dadas por esse estudo, pontua-se que trabalhos posteriores podem ser desenvolvidos no intuito de averiguar problematizações que, a princípio, irromperam durante o desenvolvimento desta pesquisa. Uma delas é o relacionamento entre família e escola/família e estudante. Ademais, sobre as limitações encontradas, destaca-se a dificuldade de liberação das participantes por seus locais de trabalho e a não problematização de algumas questões que emergiram no grupo e que poderiam ser melhor trabalhadas se mais encontros fossem possíveis.

\section{Referências}

Brasil. (2013). Presidência da República. Lei no 12.796, de 4 de abril de 2013. Recuperado em 20 de setembro de 2019, de http:// www.planalto.gov.br/ccivil_03/_Ato2011-2014/2013/Lei/ L12796.htm\#artl

Brasil (2018). Lei no 13.632, de 6 de março de 2018. Recuperado em 20 de setembro de 2019, de http://www.planalto.gov.br/ccivil_03/_Ato2015-2018/2018/Lei/L13632.htm\#art1

Castanho, P. (2007). O momento da tarefa no grupo: aspectos psicanalíticos e psicossociais. Revista da SPAGESP, Ribeirão Preto, 
8(2), 13-22. Recuperado em 17 de junho de 2020, de http:// pepsic.bvsalud.org/pdf/rspagesp/v8n2/v8n2a03.pdf

Damiani, M. F. (2012). Sobre pesquisas do tipo intervenção. XVI ENDIPE - Encontro Nacional de Didática e Práticas de Ensino UNICAMP. Recuperado em 26 de outubro de 2018, de http:// www.infoteca.inf.br/endipe/smarty/templates/arquivos_ template/upload_arquivos/acervo/docs/2345b.pdf

American Psychiatric Association. (2014). DSM-5. Manual diagnóstico e estatístico de transtornos mentais. 5. ed. Porto Alegre: Artmed.

Facci, M. G. D. (2004). A periodização do desenvolvimento psicológico individual na perspectiva de Leontiev, Elkonin e Vigostski. Caderno CEDES, 24(62). Recuperado em 25 de outubro de 2018, de http://www.amop.org.br/wp-content/ uploads/2015/09/Elkonin_9_4.pdf

Fonseca, M. E. G. (2016). Vejo e aprendo: fundamentos do programa TEACCH: o ensino estruturado para pessoas com autismo. $2^{\text {a }}$ ed. Ribeirão Preto, SP: Book Toy.

Franco, Maria Laura P. B. (2012). Análise de conteúdo. 4ª ed. Brasília: Liber Livro.

Gatti, B. A. (2005). Grupo focal na pesquisa em Ciências sociais e humanas. Brasília: Líber Livro.

Hosokawa, R. R., Wiezzel, A. C. S. (2013). As contribuições do lúdico para o desenvolvimento emocional infantil no contexto escolar. Colloquium Humanarum, 10( $\mathrm{n}^{\circ}$ especial). Recuperado em 13 de novembro de 2018, de http://web.b.ebscohost. com/ehost/pdfviewer/pdfviewer?vid=3\&sid=13d77e96b269-4454-a2d0-bd19d2d76489\%40pdc-v-sessmgr02

Joinville. (2014). Concurso Público - Edital 005/2014. Secretaria de Gestão de Pessoas. Prefeitura Municipal de Joinville. Recuperado em 26 de outubro de 2018, de https://www.joinville. sc.gov.br/wp-content/uploads/2016/08/Edital-de-Concurso-P\%C3\%BAblico-n\%C2\%BA-005-2014.pdf

Kwee, C. S. (2006). Abordagem transdisciplinar no autismo: o programa teacch. Dissertação (mestrado em fonoaudiologia) - Universidade Veiga de Almeida. Rio de Janeiro.

Kwee, C. S., Sampaio, T. M. M. \& Atherino, C. C. T. (2009). Autismo: uma avaliação transdisciplinar baseada no programa TEACCH. Revista CEFAC, 11. Recuperado em 25 de outubro de 2018, de http://www.scielo.br/pdf/rcefac/vl1s2/a12vl1s2.pdf 
Lucisano, R. V., Novaes, L. DC., Sposito, A. M. P. \& Pfeifer, L. I. (2017). Avaliação do brincar de faz de conta de pré-escolares: revisão integrativa da literatura. Revista Brasileira de Educação Especial, 23(2). Recuperado em 26 de outubro de 2018, de http://www.scielo.br/pdf/rbee/v23n2/1413-6538rbee-23-02-0309.pdf

Marconi, M. A. \& Lakatos, E. M. (2003). Fundamentos da metodologia científica. $5^{\mathrm{a}}$ ed. São Paulo: Atlas.

Marques, C. L. (2012). Metodologia do lúdico na prática docente para melhoria da aprendizagem na educação inclusiva. Revista Eixo, 1(2).

Reis, A. C. \& Zanella, A. V. (2015). Psicologia Social no campo das políticas públicas: oficinas estéticas e reinvenção de caminhos. Revista de Ciências Humanas, Florianópolis, 49(1). Recuperado em 26 de outubro de 2018, de https://periodicos.ufsc.br/index.php/revistacfh/article/view/21784582.2015v49n1p17/29604

Rocha, M. L. \& Aguiar, K. F. (2003). Pesquisa-intervenção e a produção de novas análises. Psicologia: Ciência e Profissão, Brasília, 23(4). Recuperado em 26 de outubro de 2018, de http://pepsic.bvsalud.org/pdf/pcp/v23n4/v23n4a10.pdf

Salomão, H. A. S. \& Martini, M. (2007). A importância do lúdico na educação infantil: enfoque a brincadeira e a situações de ensino não direcionadas. Psicologia.pt. Recuperado em 25 de outubro de 2018, de http://www.psicologia.pt/artigos/textos/ A0358.pdf

Saviani, D. (2011). Pedagogia histórico-crítica: primeiras aproximações. $11^{\mathrm{a}} \mathrm{ed}$. Campinas, SP: Autores Associados.

Tamanaha, A. C., Chiari, B. M., Perissinoto, J. \& Pedromônico, M. R. (2006). A atividade lúdica no autismo infantil. Distúrbios da Comunicação, São Paulo, 18(3). Recuperado em 14 de novembro de 2018, de https://revistas.pucsp.br/index.php/ $\mathrm{dic} /$ article/view/11818

WHO. (2017). World Health Organization. Autism spectrum disorders. Recuperado em 02 de outubro de 2018, de http://www.who. $\mathrm{int} /$ news-room/fact-sheets/detail/autism-spectrum-disorders 